\title{
Scientific Discovery on the Way of it's Validation
}

\author{
Juan Carlos Pérez Velázquez \\ Scientific Director of Pharmaceutical Company Pharmalat SA, Guatemala
}

\begin{abstract}
For over 26 years I have been dedicated to developing a scientific discovery, which is based in quantum physics and is apply to any area of science, to develop any technology. I am a scientist and I want to validate this discovery without precedent in the history of humanity, quantum DNA, it has a range of technological possibilities.
\end{abstract}

Keywords: scientific discovery, quantum physics, science, technology, history of humanity, DNA

\section{Introduction}

Twenty-six years ago, a young university student felt the concern to find a constant that would represent an absolute truth through time, from the first civilizations to the present, versus the incompatibility of the relative truths that have prevailed until these days.

Finally, the constant was found, which is represented in the binary system through its two digits 0 and 1 , which reflect two possible states: off or on, open or closed, which represents the functional support of digital technology. This binary system is linked to the oldest civilizations, such as the Empire of Ife in Nigeria, the Ancient Egyptian Civilization and according to investigations, its starting point may have been in the periods of the First Chinese Dynasty.

The finding of this constant allowed establishing a strategy of scientific research that establishes the explanation of the two states that were mentioned previously, in other words, it explains the truth behind these conditions.

They were many years of analysis, comparisons and calculations and when the tiredness began to be felt, a source of immense wisdom was revealed, which would guide the way of thinking of human beings towards an unprecedented technological era.

Natural properties and laws that define the formation of any existence in the whole universe were found, but not only that, they could also specify the time-space principles that are established in any creation process. In other words, everything that is created within the universe is made up by properties with the binding of certain natural laws based on very precise principles of space-time.

With the Properties, Natural Laws and Principles space I was able to discover the Quantum DNA of Creation.

I think that if what I'm saying is true, this is a novelty for science, however with this discovery in particular, we can visualize for first time, the design of formation of any existence and, in this way, we can determine the following characteristics:

- It defines the functionality for which a certain existence was created.

- It defines the link or interrelation of each creation with its area of existence and its participants.

- It defines how far it goes and what the potential of existence of each creation is.
In this way we could know for any creation, its specific utility, as well as the type of relationship and how far it would come in terms of capacity and possibilities. Obviously and without any doubt we have found a source of information that will help to minimize the time of scientific research and to really know the reason of each existence in the whole universe. Therefore, the ways in which this new science can be used are different; among them we have the possibility of visualizing, for instance:

- Design of existence of each human being.

- Design of existence of each plant.

- Design of existence of each animal.

- Design of the existence of each atomic symbol.

- Biological existence design (cells, molecules, organs, systems, virus, bacteria)

- Disease existence design.

- Existence design for the antidote of each disease.

- Existence designs of each toxin.

- Design of the existence of planets, galaxies, suns.

- Design that represents a company, business, agency, project or line of research, model.

- Design that represents a government, president and form of governance.

- Design that represents each country, town, or social group.

- Design that represents each food.

- Design that represents the answer to each question. (before the unknown, before the hypothesis, to know of a group of possibilities which should be the best)

- Design that represents or visualizes how life will be for a number of years, months, weeks, or a day (hour, minute or second)

From the above, we are describing everything that could be verified or discovered, from what we supposedly know or what we do not know, from an idea to a stone.

But not only the visualization of these dissimilar designs will give us the exact idea of a certain creation in terms of its rules and conditions of existence, it will also tell us which is the wrong way, or where our error would be, what would be the level of deficiency of our valuations or decisions, in our actions, avoiding setbacks and their negative consequences.

It doesn`t matter how you think or what you propose, as long as your way of life goes out of the conditions that govern your laws and principles space time of existence, you will pay in some way your imprudence and ignorance. 


\section{International Journal of Science and Research (IJSR) \\ ISSN: 2319-7064}

Index Copernicus Value (2016): 79.57 | Impact Factor (2017): 7.296

Now, all these discoveries, led to think of a new science, which is called Genetic Vibration and is supported by the following structure:

- XL Genetic Control System: This is formed by the properties and natural laws in addition to the principles that govern space time in the creation process throughout the universe.

- Matrix XL: Quantum Computerized Intelligent System, which allows through a structure to formulate time space to visualize the design of creation that is desired, the system of formulas that is used originates from the laws and properties found, therefore nothing is made up.

- Literary Support: It consists of 13 books and 1 catalog, where all the discoveries and the results of their applications in various fields of science and society are made known.

What is intended with this new science?

Its main objective is to serve as a scientific tool to all the professionals of the world, according to the different interests.

The visualization of any creation is represented by a series of codes that need to be interpreted following a unique methodology that addresses only precise paths, which according to the capacity of the researcher can obtain a greater number of information, therefore it can't be any human, the more qualified and the more educated, there will have more conditions to extract more information, more knowledge, more revelations.

The only limitations that this new science will have besides the Professional Preparation that is needed, within the field where it is used, it will be the following:

- Any human being who is bordering on the knowledge that he or she possesses (philosophy, ideology, professional theory) is not in agreement to use the benefits of the new science.

- The tool that displays the different existing designs won`t be available to any professional or company until the 12 books have not been published and these can be acquired by most of the professionals on the world, therefore, the computerized intelligent tool will be used only by the author of this discovery, until such a condition is achieved.

As a summary we could say the following:

1) Natural properties unknown by humanity are disclosed.

2) Natural laws unknown by humanity are disclosed.

3) Space-time principles unknown by humanity are disclosed.

4) The absolute truth that humanity needs so much is revealed for the first time, offering answers to all the questions without answers.

5) The great philosophical conflict between matter and consciousness is resolved.

6) The necessary evidences for the burial of any idealistic manifestation are shown.

7) Through the customization of molds can be taught to each human being the path to travel according to their own unique design of creation.
8) Humans will be able to know the reason of each existence in the whole universe.

9) Humans will be able to know the bases of creation, its evolutionary continuity and its final goal.

10) It polishes, adjusts, or rectifies the conceptual level according to its time space.

11) It will be possible to know the mysteries of the conscience and the reason of its existence.

So far we have seen only the introductory part, in future editions we will continue giving details about the diversity of applications and utilities for a technological development without precedent in the history of humanity and how the Intelligent Computer Matrix XL can be used in a new path that will revolutionize the extinction of a number of diseases that can't be cured.

\section{Author Profile}

Lic. Juan Carlos Pérez Velázquez is Independent Scientist

Volume 7 Issue 10, October 2018 